\title{
Effects of Agility Training with Kinesio Taping on Muscle Tone, Muscle Strength Lower Extremity and Dynamic Stability in Women Softball Players
}

\author{
Kyunghun Kim ${ }^{a, b *}(\mathbb{D})$ Hyeonhee $\operatorname{Kim}^{a, b}(\mathbb{D}$ \\ ${ }^{2}$ Department of physical therapy, Gimcheon University \\ ${ }^{b}$ Gimcheon institute of rehabilitation science, Gimcheon University
}

Objective: The aim of this study was to investigate the effect of agility training with kinesio taping (ATKT) on muscle tone, muscle strength lower extremity and dynamic stability of women softball players.

Design: Two groups pre-post randomized controlled design

Methods: 34 softball players were recruited randomly assigned into the ATKT group and agility training with sham kinesio taping (control group). All subjects performed agility training for $30 \mathrm{~min} /$ day, 5 times/week for 4 weeks. The subjects in the ATKT group underwent agility trainingwith kinesio taping on vastus madialis, vastus medialis, rectus femoris, and vastus lateralis where the subects in the control group underwent agility trainingwith sham kinseio taping.

Muscle tone was measured using myotonPRO. A Hand dynamometer was used to evaluate muscle strengthening of lower -extremity. Dynamic stability was measured using the side hop test.

Results: Muscle tone of lower-extremity was significantly more increased in the ATKT group (mean change $0.39 \pm 0.31$ ) than in the control group (mean change $0.19 \pm 0.31)(p<0.05)$. Muscle strength of lower-extremity was significantly more increased in the ATKT group than in the control group $(\mathrm{p}<0.05)$. Dynamic stability was significantly more increased in the ATKT group (mean change $-1.39 \pm 0.45)$ than in the control group (mean change $-0.60 \pm 0.46)(\mathrm{p}<0.05)$.

Conclusions: We confirmed that the benefits that ATKT is effective for increasing in softball players and suggested that knee joint kinesio taping. Also, it was observed improvement of muscle tone, muscle strength and Dynamic stability.

Key Words: Agility, Kinesio taping, Softball, Muscle tone, Muscle strength, Dynamic stability

서론

소프트볼은 야구에서 파생된 재미적인 요소와 경쟁적 인 요소를 가진 팀 스포츠이다. 소프트볼에서 경기력을 높이기 위해서는 선수들의 민첩성, 근력, 지구력, 포지션 별 다른 체격, 그리고 체력적인 요소가 필요하다[1].

특히 야구와 소프트볼 같은 종목에서는 힘을 한 번에 쓰는 폭발력, 민첩성, 스피드가 선수의 능력과 성적을 예 측하는데 가장 큰 요소이다[2].

소프트볼은 수비면에서 본다면 더 좋은 스피드와 반응 속도, 민첩성이 높은 선수가 필드에서 더 넓은 면적에 대
해 담당할 수 있고, 이는 상대팀의 안타와 잠재적인 득점 기회를 없앨 수 있는 것이다. 공격면에서 본다면 투수에 게서 시작된 공을 맞춘 다음 최대한 빠르게 1 루에 도착하 기 위해 배팅 후 발 동작, 달릴 때의 발의 스피드, 민첩성 등 신체적 역학을 잘 갖추어야 한다 $[2,3]$. 도루는 수비면 에서 본다면 달리는 상대의 주자를 정해진 시간안에 투수 에서 포수에게 포수에서 2, 3 루에게 공이 전달되어야 상 대의 공격을 저지할 수 있다. 공격면에서 본다면 투수가 공을 던지는 동작에서부터 2루까지 3.6초안에 도달해야 한다고 하였다. 따라서 수비와 공격 양쪽면에서 스피드와 민첩성은 중요한 요소이다[4]

Received: Dec 19, 2021 Revised: Dec 27, 2021 Accepted: Dec 28, 2021

Corresponding author: Kyunghun Kim (ORCID https://orcid.org/0000-0002-5889-1948)

Department of Physical Therapy, Gimcheon University

214, Daehak-ro, Gimcheon-si, Gyeongsangbuk-do 39528, Republic of Korea

Tel: +82-54-420-4068 Fax: +82-54-420-4467 E-mail: huni040@naver.com

This is an Open-Access article distributed under the terms of the Creative Commons Attribution Non-Commercial License (http://creativecommons.org/licenses/ by-nc/4.0) which permits unrestricted non-commercial use, distribution, and reproduction in any medium, provided the original work is properly cited.

Copyright $(2021$ Korean Academy of Physical Therapy Rehabilitation Science 
민첩성은 종종 방향을 빠르게 바꾸고 출발하고 빨리 멈 출 수 있는 능력으로 인식되며, 계속 변화하는 환경이나 예측할 수 없는 자극 등에 대응하여 실행되는 기술이고 이것은 끊임없는 적응에 의해 지각, 의가결정 능력, 신속 한 반응 능력이 필요하다 $[5,6]$. 따라서 단순히 방향을 바 꾸는 속도를 높이는 훈련보다 민첩성의 지각적인 요소와 의사결정의 요소를 포함한 형태의 열린 운동 기술 훈련을 해야 한다[7].

스포츠에서 최적의 경기력을 위해서는 민첩성이 핵심 요건이며, 다양한 스포츠의 경기 능력의 수준을 측정 및 구별할 수 있는 피트니스적 특성이라는 것이 확인되었다 [8-10]. 민첩성이 중요한 역할을 하는 만큼 선수의 경기력 에 큰 영향을 미치고 민첩성의 차이는 선수의 능력 평가 에 큰 영향을 미친다. 발목이나 무릎 같은 부위에 부상이 생긴다면 선수의 움직임의 안정성과 균형을 잃어 활동의 제한을 받을 수 있다. 때문에 키네시오 테이프의 사용은 경기에 복귀할 수 있는 우수한 단기치료, 운동선수들의 경기력 향상에 도움이 된다고 보고되었다[11].

테이핑은 관절을 보호하는데 일반적으로 사용된다. 급 성기 동안 추가적인 손상 방지, 부종억제, 움직임 제한을 한다. 더해 힘과 즉각적인 반응의 능력과 운동수행능력을 발달시킨다. 테이프는 두가지로 나뉘는데 비탄력테이프 (athletic tap), 탄력테이프(kinesio tap)이다[12]. 그 중 탄 성테이프(kinesio tap)는 더 얇고 비탄력테이프(athletic)에 비해 신축성이 뛰어나고 관절가동범위의 제한을 피할 수 있다는 것이 특징이다[13].

한국의 소프트볼 역사는 그리 길지 않다. 한국 전체의 소프트볼 인구는 대한 야구소프트볼 협회에 2021년도 등 록 완료 기준 활동하는 선수는 400 여명에 그친다. 때문에 소프트볼 선수를 대상으로 한 많은 연구들은 서양을 중심 으로 진행되어왔고 비교적 비인기 종목에 속하는 한국에 서는 소프트볼 선수들을 대상으로 하는 연구가 턱없이 부 족한 것이 현실이고 더욱이 선수들의 운동수행 능력향상 에 관한 연구는 부족한 실정이다.

따라서 본 연구의 목적은 국내 소프트볼 선수의 기능향 상, 경기력 향상을 위해 여자 소프트볼 선수들을 대상으 로 키네시오 테이핑을 적용한 민첩성 훈련이 하지 근긴장 도, 하지 근력, 그리고 동적 안정성의 미치는 영향을 알아 보고자 한다.

\section{연구방법}

\section{연구대상}

본 연구는 대구에 위치한 대구대학교와 대구 도시공사 의 소프트볼 선수 34 명을 대상으로 실험을 진행하였다. 연구대상자의 선정조건은 다음과 같다. 1) 소프트볼 선수
경험이 있고 선수 경력이 5년 이상인 자 2) 연령이 20 30 대 미만인 자 3) 신경계, 심폐계, 그리고 근골격계의 병력 이 없는 자 5) 본 연구에 적극적으로 참여할 의사가 있는 자로 선정하였다. 대상자 제외조건은 다음과 같다. 1) 무 릎이나 다리의 수술이나 다른 물리치료를 시행하는 자 2) 최근 30 일 이내에 스테로이드 주사나 약을 복용하는 자 3) 키네시오 테이핑의 알러지 반응이 있는 자를 제외하였 다. 본 연구에 대해 모든 절차와 중재방법을 설명하고 자 필로 서명한 동의서를 받았으며 연구 위원회 승인을 받아 연구를 진행하였다(GU-202104-HRa-04-02-P).

연구절차

본 연구는 단일 맹검법을 적용하였으며 두 집단 사전사후 무작위설계방법으로 구성하였다. 대상자의 편견을 최 소화하기 위하여 Randomizer (https://www.randomizer.org) 를 사용하였으며 키네시오 테이핑을 병행한 민첩성 훈련 그룹, 위약 키네시오 테이핑을 병행한 민첩성 훈련 그룹 으로 무작위 배정을 하였다. 모든 대상자들은 1 일, 30 분, 1 주 5 번, 총 4 주간 총 20 회 훈련을 적용하였다. 실험 전, 실험 4주 후에 하지 근긴장도, 하지 근력 그리고 동적 안 정성을 평가하였다. 각 환자의 그룹과 정보에 대해서 알 지 못하는 임상경력이 5 년 이상의 물리치료사 3 명이 중 재, 분석, 그리고 평가를 진행하였다.

\section{중재방법}

키네시오 테이핑을 병행한 민첩성 훈련 그룹(agility training with kinesio taping: ATKT)은 키네시오 테이핑을 부착 한 상태에서 5 가지 민첩성 훈련을 한 그룹을 말한다. 테 이프는 탄성력이 있는 오리지널 키네시오 테이프 (Kinesio Tex Tape, Kinesio Holding Corporation, Albuquerque, $\mathrm{NM}, \mathrm{USA}$ )를 사용하였다. 테이프는 Vithoulka 등[14]의 부착 방법을 수정, 보완하여 (1) 안쪽넓은근은 무릎뼈의 안쪽측면에서 안쪽 $3 \mathrm{~cm}$ 와 위쪽 $4 \mathrm{~cm}$ 의 수직 $55^{\circ}$ 를 향해 부착하였다. (2) 가쪽넓은근은 무릎뼈의 기저부에서 위쪽 $10 \mathrm{~cm}$ 와 가쪽 $8 \mathrm{~cm}$ 의 수직 15 도를 향해 부착하였다. (3) 넙다리곧은근은 무릎뼈 정중앙에서 위앞엉덩빼가시를 향 해 반듯하게 부착하였고 테이프의 탄력도는 $10 \sim 15 \%$ 로 설정하였다.

대조군(agility training with sham kinesio: control group)은 위약 키네시오 테이핑을 부착한 상태에서 5 가지 민첩성 훈련을 한 그룹을 말한다. 테이프는 탄성력이 있는 오리지널 키네시오 테이프 (Kinesio Tex Tape, Kinesio Holding Corporation, Albuquerque, NM, USA)를 사용 하였고, 무릎뼈 위 넙다리네갈래근을 횡으로 향하도록 부 착하였다. 
두 그룹 모두 같은 훈련을 실시하였으며, 민첩성 훈련 은 Mitchel 등[1]이 제시한 훈련 방법을 수정 보완하여 실시하였다. 민첩성 훈련은 볼 드롭, 사이드 스텝 볼 캐치, 네 방향스텝 볼 캐치, Y자 볼 캐치, 무작위 볼 캐치 5 개 로 구성되었으며 각 훈련은 1 회 수행 시 5 초 이내에 수행 하도록 하고 각 훈련은 10 회 진행하였다. 각 훈련을 마치 고 다음 훈련으로 이동하는 동안에는 1 분에 시간을 주어 이동과 휴식을 같이 하도록 하여 1 일 훈련 시간은 30 분으 로 하였다.

(1) 볼 드롭은 스타트 위치에 뒤돌아 대기하고 코치는 공을 들고 선수로부터 $10 \mathrm{M}$ 떨어진 곳에서 신호(소리)를 주면 선수는 코치를 행하여 뛰고 코치는 선수가 적당한 위치를 통화할 때 공을 놓아 선수가 그 공을 잡도록 한다. 이 때 코치는 선수에게 신호(소리)에 반응에 최대한 빠르 게 반응하고 떨어지는 공의 위치(시각, 거리감각)을 파악 할 수 있도록 지시한다.

(2) 사이드 스텝 볼 캐치는 $5 \mathrm{M}$ 간격의 표시 중앙에 선 다. 코치는 두 개의 공을 가지고 선수의 정면 $10 \mathrm{M}$ 떨어 진 곳에서 선수가 준비가 되면 양 옆의 표시에 첫 번째 공 을 선수가 준비가 되면 양 옆의 표시에 첫 번째 공을 랜덤 방향으로 보낸다. 선수는 사이드 스텝으로 이동하여 볼을 잡고 빠르게 방향전환하여 반대쪽 표시로 사이드 스텝이로 이동하여 나머지 공을 잡는다. 이 때 코치는 선수에게 빠 른 방향 전환과 정확한 볼 캐치를 하도록 지시한다.

(3) 네 방향 스텝 볼 캐치는 $5 \mathrm{M}$ 의 정사각형의 모서리 에 표시를 두고 정중앙에 선수가 선다. 선수의 $10 \mathrm{M}$ 전 방에 코치가 서고 네 곳의 모서리를 향하여 공을 던지면 선수가 공을 향해가고 공을 잡은 선수는 코치의 소리명령 에 따라 정해진 목표에 공을 던질 수 있도록 몸을 빠르게 회전시킨다. 이 때 코치는 선수에게 빠르게 방향 전환을 지시한다.

(4) $\mathrm{Y}$ 자 볼 캐치 $9 \mathrm{M}$ 간격의 $\mathrm{Y}$ 자 형태로 표시하고 글 자의 아랫부분 하나의 표시에서 선수는 대기한다. 코치는 표시가 벌어지는 윗부분에서 조금 더 떨어진 곳에서 공을 가지고 선다. 선수는 앞의 표시까지 전력으로 뛰어가고 두번째 표시에 도달할 때 즈음 코치는 양쪽의 두 표시 중 랜덤으로 공을 던지면 선수는 빠르게 목표의 방향을 틀어 공을 잡을 수 있도록 노력해야한다. 이 때 코치는 선수에 게 공의 위치를 확인하고 빠르게 이동할 것을 지시한다.

(5) 무작위 볼 캐치는 선수들의 각 포지션 또는 어느 위치에 서게 하고 그 앞의 $5 \mathrm{M}$ 간격을 두고 코치가 선 다음 두개의 지점에 표시한다. 코치는 공을 개수(횟수), 위치를 랜덤으로 하여 선수를 향해 던지고 선수는 공의 위치에 따라 볼을 캐치한 다음 코치의 지시에 따라 정해 진 곳에 공을 던진다. 이 때 코치는 선수에게 볼을 캐치한 다음 몸통의 회전을 빠르게 함과 동시의 공을 던질 수 있
는 자세를 정확하게 취하도록 지시한다.

휴식시간은 민첩성 훈련은 수행하는 시간 대비 $1: 5$, $1: 20$ 으로 할 수 있으나, 수행시간이 짧아 휴식시간의 영 향은 크지 않다[1]. 각 종목별 반복횟수는 5 회로 하였으 며, 훈련 전 충분한 스트레칭과 워밍업을 마친 상태로 진 행하였다.

키네시오 테이핑의 적용 시간은 두 그룹 모두 $\operatorname{Lim}$ 등 [15]의 키네시오 테이핑 적용시간을 수정, 보완하여 48시 간을 기준으로 부착되어 있던 기존의 키네시오 테이프를 제거하고 다시 적용하는 방법으로 진행하였다.

측정방법 및 도구

하지 근긴장도

근긴장도의 측정은 MyotonPRO를 사용하여 측정하였 다(Myodon Ltd, Lond-on and Myoton AS, Estonia). 측 정은 Multiscan 모드로 Tap의 반복횟수 5 회, 피하 조직 층의 사전 압축력 $0.18 \mathrm{~N}$, 단일 기계적 충격 시간 $15 \mathrm{~ms}$, 힘 $0.4 \mathrm{~N}$ 을 기반으로 한다[16]. 측정 위치는 넙다리곧은근 무릎뼈 정중앙과 골반의 아래앞뼈가시 사이의 위쪽 3 분지 1지점에서 측정하였다. 측정기는 근육과 직각을 유지시키 면서 측정하도록 하였다[17-19]. 대상자들은 배와 가슴이 하늘로 향하는 바로 누운 자세로 눕게 하였고, 측정 중에 는 대상자들이 불필요한 동작을 하지 않도록 지시하였다.

\section{하지의 근력 검사}

본 연구에서는 하지의 무릎관절 폄근육의 디지털 근력 계를 사용하여 근력을 측정하였다. 측정방법은 대상자를 앉은 자세에서 발목관절을 최대한 발등굽힘을 한 후 무릎 을 $180^{\circ}$ 까지 폄한 상태에서 최대 등척성 수축 시 나타나 는 압력을 측정하였다. 연습 1 회 실시 후 각 3 회씩 측정 값을 평균을 기록하였다. 1 회 10 초 측정 후 15 초의 휴식 을 주어 근 피로가 배재되도록 한 후 측정하였다. 측정자 내 신뢰도, 측정자 간 신뢰도는 각각 $\mathrm{r}=0.90 \sim 0.96, \mathrm{r}=$ $0.76 \sim 0.97$ 이고, 디지털 근력계는 $0.99 \%$ 이다[20].

\section{하지의 동적안정성 (side hop test)}

사이드홉 테스트는 Docherty 등[21]에 개발되었으며 테스트의 방법은 $30 \mathrm{~cm}$ 간격을 두고 뛰었다가 다시 시작 자리로 돌아오는 방법으로 왕복하는 것을 1 회로 하여 10 회 왕복하는 시간을 0.01 초 단위로 측정하였다. 측정 시, 선을 밟을 경우, 주어진 거리를 넘지 못했을 때 실패로 보 고, 휴식 후 다시 하였다[22]. 측정횟수는 2 번 측정하였으 며, 성적이 높은 기록을 평가기준에 적용하였다. 사이드홉 테스트는 높은 신뢰도 $(\mathrm{ICC}=0.84)$ 를 가지고 있다[21]. 
자료분석

본 연구의 모든 통계적 분석은 SPSS(Version 20.0, Chicago, Illinoi)를 이용하였다. 정규성 검정은 Shapori-Wilk 검정을 실시하였다. 독립표본 t검정과 카이제곱 검정을 사 용하여 대상자의 일반적특성과 두 그룹 간 종속변수의 사 전 값에 대한 동질성을 평가하기 위하여 사용하였다. 그 룹간 키네시오 부착 부위와 민첩성 훈련에 따른 변화량을 알아보기 위하여 독립표본 t검정을 사용하였다. 각 그룹내 사전 사후의 차이 값을 알아보기 위하여 대응표본 $\mathrm{t}$ 검정 을 사용하였다. 모든 통계적 유의수준 $(\alpha)$ 은 0.05 이하로 설정하였다.

\section{연구결과}

연구대상자의 일반적인 특성

키네시오 테이핑을 병행한 민첩성 훈련 그룹과 위약 키 네시오 테이핑을 병행한 민첩성 훈련 그룹의 일반적인 특 성에 대한 두 군 모두 동질한 것으로 나타났다. 연구대상 자의 일반적인 특성은 표 1 과 같다.

\section{하지 근긴장도 변화}

하지 근긴장도 변화에서 ATKT 그룹은 실험 전 14.00
$\mathrm{Hz}$ 에서 실험 후 $14.39 \mathrm{~Hz}$ 으로 $0.39 \mathrm{~Hz}$ 의 유의한 향상을 보였고 $(\mathrm{p}<0.01)$, 대조군에서는 실험 전 $13.73 \mathrm{~Hz}$ 에서 실 험 후 $13.93 \mathrm{~Hz}$ 으로 $0.19 \mathrm{~Hz}$ 의 유의한 향상을 보였다 $(\mathrm{p}$ $<0.05)$. 또한 키네시오 부착 부위와 민첩성 훈련에 따른 그룹간 비교에서 ATKT 그룹이 대조군 보다 통계학적으 로 유의한 차이를 보였다 $(\mathrm{p}<0.05)$.

하지 근력 변화

하지 근력의 변화는 넙다리네갈래근과 장딴지근안쪽갈 래의 변화를 측정하였다.

넙다리네갈래근의 근력 변화에서 ATKT 그룹은 실험 전 $93.37 \mathrm{~N}$ 에서 실험 후 $106.14 \mathrm{~N}$ 으로 $12.77 \mathrm{~N}$ 의 유의 한 향상을 보였고 $(\mathrm{p}<0.01)$, 대조군에서는 실험 전 91.30 $\mathrm{N}$ 에서 실험 후 $98.82 \mathrm{~N}$ 으로 $7.52 \mathrm{~N}$ 의 유의한 향상을 보 였다 $(\mathrm{p}<0.05)$. 또한 ATKT 그룹과 대조군 그룹간 비교 에서 ATKT 그룹이 대조군 보다 통계학적으로 유의한 차 이를 보였다 $(\mathrm{p}<0.05)$.

장딴지근안쪽갈래의 근력 변화에서 ATKT 그룹은 실 험 전 $165.30 \mathrm{~N}$ 에서 실험 후 $178.85 \mathrm{~N}$ 으로 $13.55 \mathrm{~N}$ 의 유의한 향상을 보였고 $(\mathrm{p}<0.01)$, 대조군에서는 실험 전 $162.16 \mathrm{~N}$ 에서 실험 후 $171.03 \mathrm{~N}$ 으로 $8.86 \mathrm{~N}$ 의 유의한 향상을 보였다 $(\mathrm{p}<0.01)$. 또한 ATKT 그룹과 대조군 그 룹간 비교에서 ATKT 그룹이 대조군 보다 통계학적으로

Table 1. General Characteristics of Participants

$(n=34)$

\begin{tabular}{llll}
\hline & ATKT group $(\mathbf{n}=\mathbf{1 7})$ & Control group $(\mathbf{n}=\mathbf{1 7})$ & $\mathbf{p}$ \\
\hline Age $($ year $)$ & $21.41(1.12)$ & $21.59(1.80)$ & 0.735 \\
Height $(\mathrm{cm})$ & $164.82(7.58)$ & $163.88(4.59)$ & 0.665 \\
Weight $(\mathrm{kg})$ & $66.99(10.01)$ & $70.88(13.25)$ & 0.341 \\
BMI $\left(\mathrm{kg} / \mathrm{m}^{2}\right)$ & $24.56(2.23)$ & $26.24(3.87)$ & 0.132 \\
Career (year) & $7.29(1.40)$ & $7.35(1.87)$ & 0.918 \\
Dominant leg (right/left) & $13 / 4$ & $14 / 3$ & 0.671 \\
\hline
\end{tabular}

The values are presented mean (SD)

ATKT group: agility training with kinesio taping, Control group: group: agility training with sham kinesio taping.

Table 2. Comparison of muscle tone of lower extremity

$(n=34)$

\begin{tabular}{lllll}
\hline & & ATKT group $(\mathbf{n}=17)$ & Control group $(\mathbf{n}=\mathbf{1 7})$ & $\mathbf{t}(\mathbf{p})$ \\
\hline \multirow{4}{*}{ RFMT $(\mathrm{Hz})$} & Pre & $14.00(0.68)$ & $13.73(0.90)$ & $0.982(0.333)$ \\
& Post & $14.39(0.62)$ & $13.93(0.91)$ & \\
& $\Delta$ & $0.39(0.31)$ & $0.19(0.31)$ & $2.147\left(0.039^{*}\right)$ \\
& $\mathrm{t}(\mathrm{p})$ & $-5.214\left(0.000^{*}\right)$ & $-3.715\left(0.002^{*}\right)$ & \\
\hline
\end{tabular}

The values are presented mean (SD)

ATKT group: agility training with kinesio taping, Control group: group: agility training with sham kinesio taping.

RFMT: Rectus femoris muscle tone. ${ }^{*} \mathrm{p}<0.05$. 
Table 3. Comparison of quadriceps and soleus muscle power

$(\mathrm{n}=34)$

\begin{tabular}{lllll}
\hline & & ATKT group $(\mathbf{n}=\mathbf{1 7})$ & Control group $(\mathbf{n}=\mathbf{1 7})$ & $\mathbf{t}(\mathbf{p})$ \\
\hline \multirow{2}{*}{ Quadriceps muscle } & Pre & $93.37(7.49)$ & $91.30(12.32)$ & $0.594(0.557)$ \\
power (N) & Post & $106.14(7.14)$ & $98.82(10.81)$ & \\
& $\Delta$ & $12.77(5.32)$ & $7.52(8.09)$ & $2.234\left(0.034^{*}\right)$ \\
& $\mathrm{t}(\mathrm{p})$ & $-9.901\left(0.000^{*}\right)$ & $-3.835\left(0.001^{*}\right)$ & \\
\hline \multirow{2}{*}{ Soleus muscle } & Pre & $165.30(15.67)$ & $162.16(15.06)$ & $0.594(0.556)$ \\
power (N) & Post & $178.85(14.56)$ & $171.03(12.97)$ & \\
& $\Delta$ & $13.55(6.56)$ & $8.86(5.13)$ & $2.323\left(0.027^{*}\right)$ \\
& $\mathrm{t}(\mathrm{p})$ & $-8.523\left(0.000^{*}\right)$ & $-7.118\left(0.000^{*}\right)$ & \\
\hline
\end{tabular}

The values are presented mean (SD)

ATKT group: agility training with kinesio taping, Control group: group: agility training with sham kinesio taping. QMP: quadriceps muscle power, SMP: soleus muscle power. ${ }^{*} \mathrm{p}<0.05$

Table 4. Comparison of side hop test

$(n=34)$

\begin{tabular}{lllll}
\hline & & ATKT group $(\mathbf{n}=\mathbf{1 7})$ & Control group $(\mathbf{n}=\mathbf{1 7})$ & $\mathbf{t}(\mathbf{p})$ \\
\hline \multirow{3}{*}{ SHP $(\mathrm{sec})$} & Pre & $10.39(1.73)$ & $10.67(2.34)$ & $-0.402(0.690)$ \\
& Post & $9.00(1.70)$ & $10.06(2.29)$ & \\
& $\triangle$ & $-1.39(0.45)$ & $-0.60(0.46)$ & $-5.013\left(0.000^{*}\right)$ \\
& $\mathrm{t}(\mathrm{p})$ & $12.607\left(0.000^{*}\right)$ & $5.441\left(0.000^{*}\right)$ & \\
\hline
\end{tabular}

The values are presented mean (SD)

ATKT group: agility training with kinesio taping, Control group: group: agility training with sham kinesio taping. SHP: side hop test. ${ }^{*} \mathrm{p}<0.05$.

유의한 차이를 보였다 $(\mathrm{p}<0.05)$.

동적안정성 변화

동적안정성의 변화에서 ATKT 그룹은 실험 전 10.39 $\mathrm{sec}$ 에서 실험 후 $9.00 \mathrm{sec}$ 으로 $-1.39 \mathrm{sec}$ 의 유의한 항상을 보였고 $(\mathrm{p}<0.01)$, 대조군에서는 실험 전 $10.67 \mathrm{sec}$ 에서 실 험 후 $10.06 \mathrm{sec}$ 으로 $-0.30 \mathrm{sec}$ 의 유의한 향상을 보였다 $(\mathrm{p}$ $<0.01)$. 또한 $\mathrm{ATKT}$ 그룹과 대조군 그룹간 비교에서 $\mathrm{ATKT}$ 그룹이 대조군 보다 통계학적으로 유의한 차이를 보였다 $(\mathrm{p}<0.01)$.

고찰

소프트볼 선수의 볼을 던지기 위해서는 정확한 근육의 선택적이고 효과적인 힘을 낼 수 있어야 하며 하지, 몸통, 어깨, 손목, 그리고 손가락의 근육들의 복합적인 활동이 중요하면 이중에서 특히 하지 근력에 안정성이 중요하다 [23,24]. 특히 투구시 무게중심의 이동을 통해 최대의 거 리를 획득하는데 중요한 요소로 제공된다[25].
본 연구에서는 키네시오 테이핑과 민첩성 훈련이 하지 근긴장도, 하지 근력, 그리고 동적 안정성 미치는 영향을 알아보았다. 본 연구의 주요 결과, 하지 근긴장도, 하지 근력변화, 그리고 동적 안정성에서 ATKT그룹이 대조군 보다 통계적으로 유의한 차이를 보였다.

근긴장도와 넙다리네갈래근의 이완시, 수축시 검사자내 신뢰도와 검사자간 신뢰도 매우 높은 수준이면 근긴장도 와 근력은 높은 상관관계를 나타낸다[26]. Serrã 등[27]의 연구에 따르면 근골격계 질환 이력이 없는 남성 성인 18 명을 대상으로 키네시오 테이핑 적용 후 바벨 백 스쿼트 를 조화, 억제, 위약의 세가지 조건으로 진행한 결과 유의 한 차이를 발견하지 못하였다. 이처럼 키네시오 테이핑의 효과를 입증하지 못한 연구 결과도 있는 반면 40명의 무 릎 골관절염 있는 환자를 대상으로 키네시오 테이핑을 적 용이 등속성 무릎 폄의 토크 향상, 표준화된 계단 이동 과 제, 무릎 골관절염 통증 감소에 효과적이라고 하였다[28].

만성 염증 질환을 가진 선수들 25명에게 키네시오 테 이핑 적용, 키네시오 테이핑 미적용, 비탄력성 테이핑 적 용의 3 가지 조건으로 민첩성 테스트를 무작위로 실시한 
결과 단기적 효과로 키네시오 테이핑이 발목의 관절가동 범위를 늘려주고 스포츠 경기력 향상에 적합한 개입이 되 었다[11]. 또한 Mostaghim 등[29]은 44명의 건강한 대학 선수들을 대상으로 수직 점프, 민첩성 및 스프린트를 사 용하여 평가하였고, 키네시오 테이핑이 최대 자발 등척성 수축, 점프, 민첩성, 스프린트 등에 긍정적인 영향을 미쳤 다. 이처럼 넙다리갈래근의 키네시오 테이핑이 근육의 수 축, 필요한 근육으로 활동할 수 있도록 역할을 해주었고 키네시오 테이핑의 감각입력, 민첩성 훈련이 근육계와 신 경계의 조화로운 반응이 유도되어 상호작용의 효과가 증 가하였다고 사료된다.

키네시오 테이핑은 관절, 근육을 보호 또는 고정만을 하기 위해 병원 등 임상과 수많은 스포츠 현장에서 사용 되고 있다. 더불어 근력과 근지구력 등 근육의 기능을 향 상시키는 목적으로 사용되고 있다[30]. 평범한 여성에게 키네시오 테이핑을 적용하여 동심성 운동과 편심성 운동 을 실시하였는데 그 결과 키네시오 테이핑을 적용한 그룹 이 적용하지 않은 그룹과 비교해 편심성 근력이 향상되었 음을 확인할 수 있었다[14]. 키네시오 테이핑의 중재와 병 행한 스쿼트 운동은 10 명의 무릎관절의 환자를 대상으로 오픈 체인 운동과 크로스 인 운동인 스쿼트를 실시 한 결 과, 크로스체인 운동에서 안쪽넓은근의 활성도가 유의미 하게 더 높았다고 하였다[31]. 이는 키네시오 테이핑이 부 상방지와 재활에만 국한되지 않고 근육의 능력을 키우는 트레이닝에도 적극 활용될 수 있다는 주장의 근거가 될 수 있다[30]. 키네시오 테이핑의 효과의 기전으로는 키네 시오 테이핑 적용이 부착 부위에 한 번에 많은 숫자의 시 냅스 전 신경섬유가 탈분극 되면서 생기는 공간의 가중효 과(spatial summation, additive effect)으로 인해 협력작 용이 활발해지면서 근육의 장력이 증가되어 근력이 향상 되었다고 생각할 수 있고, 키네시오 테이프의 부착을 통 해서 근육에 더해지는 자극의 강도에 의해 근육의 반응이 라 말할 수 있는 수축력의 증가를 발생시켰다고 사료된다.

Miller 등[32]의 연구에서 복잡하고 다양한 움직임을 하는 동안 몸의 균형 능력과 위치 제어 능력을 강화하면 민첩성도 같이 향상될 것이라고 말했고, Nimphius 등[33] 의 연구를 보면 상대적인 근육의 힘과 여자 소프트볼 선 수에게 505 개의 시험 변이를 사용하여 측정된 민첩성 능 력 사이에 높은 상관관계가 있음을 발견하였다. 또한 키 네시오 테이핑 적용이 무릎 보호대 단독 사용과 키네시오 테이핑과 무릎 보호대를 병행 했을 때 등속성 무릎 폄의 최대 토크와 싱글 레그 홉 거리를 늘리는 데 더 효과적이 라고 하였다[34]. 다른 질환에서도 24 명의 무릎관절 관련 질환의 환자를 대상으로 6 주간 키네시오 테이핑을 병행하 고 등속성 운동을 실시한 결과 넙다리네갈래근의 근력과 무릎관절의 안정성이 향상된 논문과 일치한다[35].
이는 피부의 감각 수용기에서 시작되어서 척수수준에 서 나타나는 상호신경지배 현상이 일어나는 효과라 생각 된다 $[36,37]$. 또한 고유수용성 자극을 통해 피부와 근막 사이에 공간을 넓혀 위치와 기능적으로 제한된 근육경련 의 완화, 관절의 가동범위를 증가시키고 다발성 근 수축 의 개선으로 근육의 강도 근육 긴장도를 감소시켰다고 생 각된다[38].

본 연구의 제한점으로는 대상자의 수 가 적어 일반화시 키는데 어려운 점이 있으며 키네시오 테이핑을 병행한 민 첩성 운동의 추적 연구를 실시하지 못하였다. 그리고 하 지의 근 피로도를 측정하지 못하였다. 따라서 추후 연구 에는 이런 점을 보완하여 키네시오 테이핑의 효과를 증명 하고 많은 참가자들의 대상으로 연구하여 차이점을 규명 해야 할 것이다.

\section{결론}

본 연구에서 키네시오 테이핑을 결합한 민첩성 훈련이 여자 소프트볼 선수의 하지 근긴장도, 하지 근력, 그리고 동적안정성에 미치는 영향을 비교하여 다음과 같은 결론 을 얻었다. 본 연구 결과 키네시오 테이핑을 결합한 민첩 성 훈련이 대조군 보다 하지 근긴장도, 하지 근력, 그리고 동적 안정성에서 통계학적으로 유의한 차이를 보였다. 향 후 여자 소프볼 선수의 하지 근긴장도, 하지 근력, 그리고 동적안정성의 효과를 입증하기 위해서는 키네시오 테이핑 을 결합한 민접성 적용 훈련이 스포츠 선수들의 기능 향 상 프로그램에서 사용될 수 있을 것이다.

\section{이해충돌}

본 연구의 저자들은 연구, 저작권, 및 출판과 관련하여 잠재적인 이해충돌이 없음을 선언합니다.

참고문헌

1. Magrini M, Dawes JJ, Spaniol FJ, Roberts, A. Speed and Agility Training for Baseball/ Softball. Strength Cond J. 2018;40:68-74.

2. Szymanski DJ. Collegiate Baseball In-Season Training, Strength Cond J. 2007; 29: 68.

3. Hammer E. Preseason Training for College Baseball, trength Cond J. 2009;31:79-85.

4. Hoffman JR, Vazquez J, Pichardo N, Tenenbaum G. Anthropometric and Performance Comparisons in Professional Baseball Players. JRes. 2009;23:2173-8. 
5. Little T, Williams A. Specificity of acceleration, maximum speed and agility in professional soccer players. JRes. 2005; 19:76-8.

6. Sheppard JM, Young WB. Agility literature review: Classifications, training and testing. J. 2006;24:919-32.

7. Serpell BG, Young WB, Ford M. Are the Perceptual and Decision-Making Components of Agility Trainable? A Preliminary Investigation. JRes. 2011;25:1240-8.

8. Sheppard JM, Young WB, Doyle TLA, Sheppard T A, Newton RU. An evaluation of a new test of reactive agility and its relationship to sprint speed and change of direction speed. SportsHealth Sci. 2006;9:342-9.

9. Farrow D, Young W, Bruce L. The development of a test of reactive agility for netball: a new methodology. J Sci Med. 2005;8:52-60.

10. Gabbett TJ. Physiological characteristics of junior and senior rugby league players, $\mathrm{Br} \mathrm{J}, 2002$; 36: 334.

11. Sarvestan J, Svoboda Z. Acute Effect of Ankle Kinesio and Athletic Taping on Ankle Range of Motion During Various Agility Tests in Athletes With Chronic Ankle Sprain. J. 2019;29:527-32.

12. Eom SY, Lee WJ, Lee JI, Lee EH, Lee HY, Chung EJ.The effect of ankle Kinesio taping on range of motion and agility during exercise in university students. Phys Ther Rehabil Sci. 2014;3:63-8.

13. Aguilar-Ferrádiz ME, Moreno-Lorenzo C, Matará -Peñrrocha GA, Garcí-Muro F, Garcí-Rís MC, Castro -Sáchez AM.Effect of a Mixed Kinesio TapingCompression Technique on Quality of Life and Clinical and Gait Parameters in Postmenopausal Women With Chronic Venous Insufficiency: Double-Blinded, Randomized Controlled Trial. Arch Phys Med Rehabil. 2014;95:1229-39.

14. Vithoulka I, Beneka A, Malliou P, Aggelousis N, Karatsolis K, Diamantopoulos K. The effects of Kinesio-Taping $^{\mathbb{R}}$ on quadriceps strength during isokinetic exercise in healthy non athlete women. Isokinet Exerc Sci. 2010;18:1-6.

15. Lim ECW, Tay MGX. Kinesio taping in musculoskeletal pain and disability that lasts for more than 4 weeks: Is it time to peel off the tape and throw it out with the sweat? A systematic review with meta-analysis focused on pain and also methods of tape application. Br J. 2015;49:1558-66.
16. Schneider S, Peipsi A, Stokes M, Knicker A, Abeln V.Feasibility of monitoring muscle health in microgravity environments using Myoton technology. Med Biol Eng Comput. 2015;53:57-66.

17. Agyapong-Badu S, Warner M, Samuel D, Stokes M. Measurement of ageing effects on muscle tone and mechanical properties of rectus femoris and biceps brachii in healthy males and females using a novel hand-held myometric device. Arch Gerontol Geriatr. 2016;62:59-67.

18. Aird L, Samuel D, Stokes M. Quadriceps muscle tone, elasticity and stiffness in older males: Reliability and symmetry using the MyotonPRO. Arch Gerontol Geriatr. 2012;55:e31-e39.

19. Ericson Morgan G, Martin R, Welch H, Morris K. Quantitative Weight Bearing and non-weight Bearing Measures of Stiffness in the Achilles Tendon and Gastrocnemius Muscles. Muscles, 2020; 10:100-10.

20. Koblbauer IF, Lambrecht Y, Van Der Hulst ML, Neeter C, Engelbert RH, Poolman RW, Scholtes VA. Reliability of maximal isometric knee strength testing with modified hand-held dynamometry in patients awaiting total knee arthroplasty: useful in research and individual patient settings? A reliability study. BMCDisord. 2011;12:1-9.

21. Docherty CL, Arnold BL, Gansneder BM, Hurwitz S, Gieck J. Functional-Performance Deficits in Volunteers With Functional Ankle Instability. J Athl Train. 2005;40:30-4

22. Caffrey E, Docherty CL, Schrader J, Klossner J. The Ability of 4 Single-Limb Hopping Tests to Detect Functional Performance Deficits in Individuals With Functional Ankle Instability, J OrthopTher. 2009;39:799-806

23. Gowan ID, Jobe FW, Tibone JE, Perry J, Moynes DR. A comparative electromyographic analysis of the shoulder during pitching: Professional versus amateur pitchers, Am J. 1987;15:586-90.

24. Oliver GD, Friesen KB, Barfield JW, Giordano KA, Bordelon NM, Anz AW, Andrews JR. Lower Extremity Pain and Pitching Kinematics and Kinetics in Collegiate Softball Pitchers. Int J. 2021;42:544-49.

25. Yamanouchi T. EMG Analysis of the Lower Extremities During Pitching in High-School Baseball. KurumeJ. 1998;45:21-5.

26. Kim SY. Intra-rater and inter-rater reliability of the 
myotonometer in the assessment of biceps brachii and quadriceps, Phys Ther Korea. 2007;14:29-36.

27. Serrã JC, Mezêcio B, Claudino JG, Soncin R, Miyashiro PLS, Sousa EP, et al. Effect of 3 Different Applications of Kinesio Taping Denko ${ }^{\circledR}$ on Electromyographic Activity: Inhibition or Facilitation of the Quadriceps of Males During Squat Exercise. JMed. 2016;15:403-9.

28. Anandkumar S, Sudarshan S, Nagpal P. Efficacy of kinesio taping on isokinetic quadriceps torque in knee osteoarthritis: a double blinded randomized controlled study. Physiother. 2014;30:375-83.

29. Mostaghim N, Jahromi MK, Shirazzi ZR, Salesi M. The effect of quadriceps femoris muscle Kinesio Taping on physical fitness indices in non-injured athletes. JPhys. 2016;56:1526-33.

30. Host HH. Scapular Taping in the Treatment of Anterior Shoulder Impingement. Phys Ther. 1995; 75:803-12.

31. Tang SF, Chen CK, Hsu R, Chou SW, Hong WH, Lew HL. Vastus medialis obliquus and vastus lateralis activity in open and closed kinetic chain exercises in patients with patellofemoral pain syndrome: An electromyographic study. Arch Phys Med Rehabil. 2001;82:1441-5.

32. Miller MG, Herniman JJ, Ricard MD, Cheatham CC, Michael TJ. The effects of a 6-week plyometric training program on agility. JMed. 2006;5:459-65.

33. Nimphius S, Mcguigan MR, Newton RU. Relationship Between Strength, Power, Speed, and Change of Direction Performance of Female Softball Players. JRes. 2010;24:885-95.

34. Aktas G, Baltaci G. Does kinesiotaping increase knee muscles strength and functional performance?. Isokinet Exerc Sci. 2011;19:149-55.

35. Hazneci B, Yildiz Y, Sekir U, Aydin T, Kalyon TA. Efficacy of Isokinetic Exercise on Joint Position Sense and Muscle Strength in Patellofemoral Pain Syndrome. Am J Phys Med Rehabil. 2005;84:521-7.

36. Math B, Dominiek B, Susan A. PNF in Practice An Illustrated Guide, Springer, Berlin, Heidelberg. 2008.

37. Burke JR, Kamen G. Changes in Spinal Reflexes Preceding a Voluntary Movement in Young and Old Adults. J Gerontol A Bio Sci Med Sci. 1996; 51:M17-M22.
38. Gramatikova M, Nikolova E, Mitova S. Nature application and effect of kinesio-taping. Activities Phys EducSport. 2014;4:115-9. 